\title{
PASSAGENS NA METRÓPOLE PAULISTANA DO SÉCULO XXI
}

\author{
EM TRÂNSITO. DOCUMENTÁRIO. ALÔ VíDEO. 98 MIN, 2005
}

de Henri Arraes Gervaiseau

PAUla MONTERO

[1] Benjamin, Walter. Passagens. Belo Horizonte/São Paulo: Editora UFMG/Imesp, 2007 [1935].

[2]Ibidem. 
Em trânsito não lança um olhar abstrato sobre a metrópole. Ao contrário do voyeur que ol ha a cidade do al to e fixa em um texto transparente a intricada reverberação da cidade, o diretor, inspirado nos escritos de Michel de Certeau 3 , a quem dedica sua obra, prefere acompanhar com sua câmera a experiência do caminhante que sente seu corpo enlaçado pelas ruas e marca com seu passo as distâncias. Em trânsito desenvolve um olhar curioso e intrometido no cotidiano dos transeuntes; é um registro de fragmentos de trajetórias de quinze personagens que circulam diariamente por São Paulo de motocicleta, de ônibus, de metrô, de carro e mesmo a pé. Ao caminhar com elas como quem chega de longe, Gervaiseau quer levantar os véus que escondem o sentido daquelas vidas em seus lugares de passagem; descobrir um mundo queé aquele no qual se vive; ter acesso aos corpos, aos gestos marcados pela cadência do tempo dos trajetos. Em trânsito com pedestres, motoristas, passageiros, motoboys a câmera registra, como um flâneur às avessas, a paisagem urbana. Essa experiência cotidiana do urbano enquanto fluxo é a epítome da metrópole. Sua figuração montada na cinética dos corpos que se movem, nos tênis e sapatos que aguardam em fila, nas cabeças que adormecem sobre os punhos enquanto esperam o tempo que passa, dessubstancializa a cidade enquanto permanência e organização material do espaço.

A Paris de 1908. "Um parisiense habituado à multidão, aos veículos, e a escolher as ruas, chegava a fazer longas caminhadas com um passo regular e muitas vezes distraído. De um modo geral, a abundância dos meios de circulação ainda não havia dado aos três milhões de homens... a idéia de que poderia deslocar-se com qualquer propósito e de que a distância é o que menos conta"4.

Mas em que momento a distância começa a contar? Quando os meios de circulação já se tornaram um imperativo da vida ordinária? No caso da região metropolitana de São Paulo, com o inchaço progressivo das periferias e a multiplicação dos veículos nas vias públicas, a distância tornou-se tempo: grande parte das horas úteis do dia de nossas personagens é consumida "em trânsito". A crônica de suas vidas está intimamente associada à vida que se leva nos meios de transporte. O relógio digital acoplado às imagens não pára de escandir o tempo: 5h13, Jandira; 6h48, Capão Redondo; 6h55, Jardim Ângela. Lugares distantes. A fluidez no tempo e a disjunção no espaço confluem. As vidas separadas de Antônio, Jucilene, Fátima se conectam na contigüidade das imagens. A sucessão rápida de personagens que caminham sugere que a metrópole é o produto de mundos paralelos mas simultâneos submetidos às mesmas contingências, que operam, contudo, cegamente uns com relação aos outros. O olho da câmera produz
[3] De Certeau, Michel.A invenção do cotidiano. Petrópolis: Vozes, 2002, p.169.

[4] Romain, Jules, apud Benjamin, op.cit., p. 487 . 
relações, compara existências, hierarquiza posições. Em silêncio ele acompanha Antônio, que sai de sua casa para apanhar o metrô. Está escuro, todos caminham, os passos ressoam no meio da rua deserta; cães latem, o trajeto é longo. A câmera acompanha o caminhante por um minuto e vinte segundos fazendo-nos sentir na carne o tempo que se esvai. Que faz o trajeto do corpo desse caminhante?

Uma embriaguez apodera-se daquele que, por um longo tempo, caminha a esmo pelas ruas. A cada passo, o andar adquire um poder crescente; as seduções das lojas, dos bistrôs e das mulheres sorridentes vão diminuindo, cada vez mais irresistível torna-se o magnetismo da próxima esquina, de uma longínqua massa de folhagem, de um nome de ruas.

Nada mais distante do flâneur do que o caminhar de Antônio. Ele não olha a cidade enquanto caminha, não há nada que seduza seus sentidos, nem mulheres sorridentes, nem bistrôs. Ele anda pelo meio do asfalto como se fosse uma calçada, as ruas não têm nomes, nem histórias. Nada distrai esse caminhar cujo destino é sempre conhecido de antemão. Não há vida na rua; ela só começa quando Antônio entra no metrô. Ali, no vagão apertado, Antônio sorri e se alegra; ali ele encontra seus companheiros de fé, canta hinos de louvor a Nosso Senhor e prega "não importa a tua condição financeira; não importa tua condição social. O que Jesus quer saber é se existe no teu coração um espaço para que ele possa adentrar". Pela janela os trilhos do trem correm velozmente. Com a Bíblia nas mãos, senhoras mais velhas e homens maduros cantam. A cidade não está na rua. Subvertendo a clássica oposição entre a casa e a rua, os meios de transporte são as passagens da metrópole: ali se fabricam corpos, o mundo interior e o exterior se fundem, as relações se objetivam em sua visibilidade corpórea. Eles são como as casas de Le Corbusier, onde "não contam nem o espaço, nem a forma plástica, apenas a relação e o entrecruzamento" 6 . As passagens são casas ou corredores que não têm o lado exterior como o sonho7. Ali no burburinho e no grito dos cânticos está finalmente a imagem do coletivo, esse ser "eternamente inquieto, eternamente agitado que vivencia, experimenta, conhece e inventa" a cidade. Ali o caminhante invisível ganha corpo. "Quando a gente entra no vagão", dizAntônio, "as pessoas conhecem a gente, olham para a gente. Devemos fazer tudo direitinho porque se fizermos alguma coisa errada tem sempre alguém aqui que te conhece, que tá te vendo, depois fica aí falando mal da gente."

O caminhante das ruas vazias é o fio de Ariadne que costura os fragmentos das vidas apresentadas pelo filme. Não sabemos para onde vai aquela mulher de verde, guarda-chuva e envelope nas mãos. Ao contrário daflânerie de Hoffmann ${ }^{8}$, que se obstinava em observaros 
seres humanos, nas tavernas e nas confeitarias, para determinar-lhes a espécie, ela caminha em silêncio, sem se voltar, sem olhar, como se fosse apenas ao encontro de seu destino. Não sabemos seu nome, nem onde mora, nem há quanto tempo está andando. As vidas das outras personagens vão aos poucos se revelando e ganhando forma, mas a imagem da mulher de verde permanece anônima com seu passo ininterrupto e sempre igual; como um espectro, ela passa repetidas vezes entre as personagens, em tomadas tão rápidas quanto um piscar de olhos, ligando, com seu andar sem-fim, umas às outras. O caminhante das ruas vazias é a própria fantasmagoria da cidade que esconde sua face perniciosa e temível.

"Aquele que vê sem ouvir fica muito mais inquieto que aquele que ouve semver. Este deve ser um fator significativo para a sociologia da cidade grande. As relações entre os homens nas grandes cidades [...] caracterizam-se por um acentuado predomínio da atividade da visão sobre a audição. E isso [...], antes de tudo, devido aos meios de comunicação públicos. Antes do desenvolvimento que tiveram, no século XIX, os ônibus, as ferrovias e os bondes, as pessoas não tinham a ocasião de poder ou dever se olhar mutuamente durante minutos ou horas sem se falar"s.

Os meios de locomoção produzem corpos que se tocam e não se comunicam. "O aglomerado de pessoas acotovelando-se umas contra as outras e a confusão do trânsito nas grandes cidades seriam insuportáveis sem um distanciamento psicológico", observa Simmel ${ }^{10}$. Essa proximidade física corporifica o coletivo e objetiva à força as relações sociais. A imposição coercitiva do coletivo na forma de multidão não produz empatia, mas, ao contrário, estimula uma reserva interior que nem o canto deAntônio e seus companheiros consegue romper. Como se um comando invisível os conduzisse, seguem um acordo coletivo de postar-se em filas, esperar, subir e descer. Os olhares se evitam, os corpos não entram em interação; o silêncio só não impera porque o ruído das máquinas se impõe. Celulares, $C D$ players tornam-se próteses da comunicação dos corpos. Jucilene, que passa três horas de seu dia dentro do ônibus, ouve sem ver. Para passar o tempo, escuta a música de Amado Batista, de quem gosta muito. Mas no triângulo espacial que organiza sua vida - sua casa no Capão Redondo, seu trabalho em Pinheiros e a travessia pelos meios de locomoção - , a rua ainda guarda um resquício de sonho: "minha maior alegria é sair na rua e falar 'oi' para os office boys", nos conta ela. Esteé o único momento em que o espaço urbano entre casa e trabalho não aparece como espaço vazio, compasso de espera ou obstáculo a ser vencido. Roni, em seu carro, explica a Gervaiseau que "para escapar do trânsito é preciso ter manha de rua". A cidade que se vê está esvaziada de significação. São
[9] Simmel, George, apud ibidem, p. 477 .

[10] Apud ibidem, p. 491. 
[11] Friedell, Egon, apud ibidem, p. 473.

[12] Curtius, Ernst Robert, apud ibidem, p. 48 o. linhas que correm velozmente pelo chão, são pontes que dão suporte ao movimento de carros e caminhões, viadutos que engolem os carros na escuridão, são ruas nas quais se busca uma estreita passagem entre veículos de toda sorte, bicicletas na contramão, carroceiros e motoqueiros. Tudo flui, tudo é pressa, tudo é rapidez. A materialidade da cidade se perde na cinética do movimento.

"Quando estava para ser construída a primeira linha alemã de trens na Baviera, a faculdade de medicina de Erlangen emitiu o seu parecer [...]:o movimento rápido provocaria [...] doenças cerebrais; mesmo a mera observação de um trem passando em velocidade poderia provocá-las"11.

A cinética do movimento é a própria imagem da existência urbana. Tal como Balzac, que, segundo Curtius, "viveu [...] uma vida marcada pela pressa desenfreada e pelo colapso prematuro" ${ }^{12}$, tudo é muito rápido na vida da periferia narrada por Kaol:

Às vezes tá com 14 anos e já é pai. Já tem que ir pra cima. Ele não tem tempo, não dá tempo. Você tá com uma menina, uma brecha que deu, a menina engravidou, f...A menina arrumou outro camarada, você vai enquadrar a menina, o cara já saca a arma, já atirou, já era, acabou, é muito rápido.

Ser ao mesmo tempo criança e adulto, não ter tempo para pensar e decidir, ser levado pelo fluxo dos acontecimentos - é preciso aprender a resistir psiquicamente.

Dissemos que a cidade está nas passagens. Se a aglomeração e a personificação do corpo social nos meios de locomoção coletivos levam ao retraimento subjetivo, o isolamento físico no interior do automóvel leva, inversamente, à exposição e elaboração da intimidade e do convívio social. Para Rita, o carro é o lugar privilegiado para conversar com suas filhas. Para Tatiana,é o momento de administrar a casa e atender os amigos pelo telefone celular de modo a organizar-se para sair no final do dia. Os meios de locomoção parecem criar certo tipo de espacialidade na qual as relações se desenvolvem em sentido inverso ao contato físico. Dá-se uma desterritorialização do processo social no qual a comunicação liga de maneira simultânea espaços paralelos separados entre si. A linha espacial construída pela narrativa do documentário segue o circuito das linhas de ônibus ou trem ligando casa e trabalho. Mas as redes de relações que emergem nos depoimentos não acompanham esse roteiro. As relações que aparecem não são nem de vizinhança, nem profissionais; os próprios meios de locomoção criam as condições de emergência de círculos sociais específicos. Roni vendeu sua moto por causa da violência no trânsito: tentaram assaltá-lo. Considera o automóvel mais seguro, embora já tenha perdido quatro 
carros. Anda armado. Fez seu círculo de amizades entre juízes, gerentes, delegados, policiais e advogados que fazem treinamento e curso de tiro. Sair com eles para atirar é como tomar uma cerveja no final do dia com os amigos. Já Fátima e Ângela, embora vivam no mesmo bairro, Jardim Ângela, se conheceram na fila do ônibus. Também aparecem, de maneira fugaz, alguns passatempos coletivos: na linha Itapevi, no começo da noite se organiza um carteado. A música também está presente. Kaol conta que, quando era office boy em 1989-1990,

"pegava o ônibus toda sexta-feira e tinha um encontro. Tinha samba no buzão das seis e meia, no buzão das sete horas. Pô!, samba de primeiríssima qualidade.Porquepravocêvoltarnasexta-feiraprasua quebrada, véio, eram três horas. Aí sim, nesse periodo, as pessoas se conheciam. Eu lembro que as pessoas levavam um radinho, um radinho não, um box mesmo, national. E aí, trouxe uma melodia pra gente ouvir...Ta-rã-rã-rana, tara-rã-nana...".

Ao contrário dos outros meios de locomoção que criam uma espécie de espacialidade própria e autocontida, a motocicleta compartilha, com o caminhante, o confronto físico com a rua. Mas a rua aqui é puro movimento. Diassis é um rapaz jovem e simpático que ganha a vida fazendo entregas. Amanhã é seu dia de pagar contas, então ele vai "arrepiar". Ele gosta muito de São Paulo. Quando anda de moto se sente livre. "Você está passando em cima de uma ponte assim... você olha. Coisa gostosa de ver. Você passando ali na velocidade, sentindo aquele vento. Chega a dar uma emoção. Você chega a arrepiar às vezes." Não são as pessoas, nem as vitrines que Diassis vê, mas o próprio movimento. $\mathrm{O}$ corpo sente a velocidade na pele e se arrepia; soberanos, os olhos vêem os carros passar embaixo e os sentidos ficam gratificados.Aliberdade nãoéidéia, nãoéemblema,éo prazer físico do próprio movimento. Embora não possa escolher aonde ir, pois são os pedidos que lhe traçam o caminho, ele se sente dono de seus próprios movimentos e de suas decisões. Mas como no caso de Virgínia Maria de Jesus, a nossa caminhante, as ruas por onde Diassis se move também estão vazias de pessoas, de sentidos e seduções. Espaço e tempo se fundem em uma mesma dimensão: a do fluxo. Aí parece residir a poesia da metrópole. "Sair quando nada nos obriga a fazê-lo, e seguir nossa inspiração como se o simples fato de virar à direita ou à esquerda já constituísse um ato essencialmente poético"13.

Tatiana também expressa o mesmo sentimento:

Quando não trabalhava, saía quando queria e como queria:porque estava emocionalmente carente de contato com as pessoas, então quando eu saía para o trânsito eu achava tudo um grande evento: eu estava vendo gente, estava vendo movimento.
[13] Jaloux, Edmond, apud ibidem, p. 479 . 
Tampouco aqui é o contato humano que atrai Tatiana, mas a imagem do movimento, a imagem das pessoas que se movem.

Mas há um outro cenário urbano central na narrativa do documentário; é o cenário do Terminal Capelinha, onde os ônibus fazem a baldeação dos passageiros. Nesse nó do fluxo dos meios de locomoção, todas as características do urbano que até aqui descrevemos ganham dimensões exponenciais. Pessoas andam depressa; tênis, botas, sapatos arrastam-se em longas filas. Nesta catedral das passagens, misto de mercado e lojas de departamentos, cria-se a ilusão de centro. Baldeação, mania de passar de uma embarcação para outra. Para tanto, ônibus entram e saem partindo em todas as direções. Pinheiros, Lapa, Jaçanã, nomes que evocam a diversidade de lugares e as múltiplas possibilidades de trajetos. De um terminal a outro é possível rodar São Paulo toda com apenas uma passagem. "Nos pontos de baldeação dos ônibus, os passageiros eram chamados por um número de ordem e tinham que se apresentar para garantir seu direito a um lugar"14.

O Terminal Capelinhaé o elo da rede de locomoção que une as periferias ao centro. Ao motorista Carlos Bugosi, conhecido como John Lennon, cabe fazer o percurso "mais social, da periferia mesmo, onde você vai buscar o povo na porta da casa dele" e o leva até o terminal, onde ele se conecta a outras linhas. Dois controladores com prática de manobristas, Aldair e Peba, organizam o caos. Eles manobram os carros e os estacionam de maneira que ocupem o espaço de maneira mais eficaz. Membros da Comissão de Prevenção de Acidentes, eles também têm o poder de impedir que os carros sem manutenção saiam para as ruas. O terminal, esse gigantesco centro nervoso da rede, é o coração da metrópole e o motor de seu fluxo. Esse movimento contínuo e ininterrupto que ele garante nos dá a percepção de que a cidade é um território homogêneo e unificado. Sem o pulsar dessas veias e artérias o espaço urbano se estilhaçaria em pequenos fragmentos. $\mathrm{Na}$ visão de Aldair e Peba, este teatro do movimento é a verdadeira porta do inferno. Trabalhando de dez a doze horas por dia, sentem a dupla pressão da vida política e da vida doméstica. Em casa, por causa da prolongada ausência, a mulher suspeita que ele tenha uma amante. No trabalho, vive a violência da luta sindical no bojo da briga pelo controle do sindicato: "Se a gente falar alguma besteira é isso aí, amanhã ou depois nóis tá com a boca cheia de formiga. Na ignorância da realidade é isso aí. Tá com a boca cheia de formiga". Após 22 anos de profissão Peba está cansado e anda pensando em tirar uma licença médica. Está levando muitos problemas para dentro de casa. Ele se vê vivendo em um caldeirão com fogo embaixo. Espera aquela explosão. $O$ trânsito, diz ele, "é feio demais esse negócio". Se Deus existe, Carlos não sabe; mas torce "para que esse homem exista mesmo porque, nesse transporte, Deus não está no meio não". 
Neste breve ensaio procurei recuperar a dimensão etnográfica da experiência urbana que as imagens deste documentário foram capazes de produzir. Acompanhando a experiência tátil da câmera, procurei decifrar a natureza propriamente dita da experiência espaciotemporal que os meios de transporte proporcionam. Sem me perguntar quem eram essas pessoas, que profissão ou posição social ocupavam, busquei focar a minha atenção em suas expressões corporais para reconhecer nelas sensações e sentimentos. Em detrimento de suas falas, que remetem as personagens a outras esferas da vida, ocupei-me principalmente com as imagens que fizeram emergir a dimensão cinética como figura dramática. O movimento faz da cidade, a cidade. E qual a natureza desse urbano? Do ponto de vista do olho que a vê, ela é o traço da linha do trem que desliza com rapidez, são fachadas que passam, viadutos que sobrepõem várias camadas de veículos cruzando em todas direções, caos, conexões, velocidade, vento. Do ponto de vista da experiência, o paradigma benjaminiano das passagens ainda pode servir de inspiração para descrever esse experimento que é a megacidade. Mediante o contraponto com os fragmentos que relatam a experiência urbana no século XIX - em que os nascentes meios de locomoção já faziam da cidade uma experiência bastante particular, na qual a distância não é mais obstáculo e a rapidez embriaga -, tentei lançar uma luz nos fragmentos de experiência capturados nas imagens deste documentário. Aqui a forma urbana deixa de ser percebida como paisagem e passa a ser tomada como objeto de deleite. Aimagem da cidade perde em substância e se torna puro movimento. O espaço arquitetônico das passagens se desloca para os próprios meios de transporte. No aperto dos corpos e na multidão das estações é possível ter a experiência objetivada do coletivo, do espaço público. Mas os deslocamentos sem propósito, tão apreciados na figura do flâneur, se tornam mais raros e difíceis. Quando acontecem, o deleite estético da experiência urbana cidade reaparece:ver as pessoas sem servisto, vero movimento, são imagens que corporificam o prazer da cidade e a idéia de liberdade que o anonimato supõe.

Mas se a etnografia cinética proposta neste documentário põe em contigüidade vidas paralelas, o que resulta dessa comparação entre existências que se desconhecem? Todas elas vivem, é certo, sob a mesma pressão do tempo. Mas os efeitos dessa pressão sobre a experiência diária são diversos. Pode-se dizer que o tempo opera diferentemente quer se ande em transporte coletivo ou em carro particular. No primeiro caso, o tempo passado nos meios de transporte subtrai o tempo usado na vida em família e no uso da cidade. No segundo caso, o tempo passado no automóvel intensifica as relações de intimidadee 
potencializa os usos múltiplos da cidade. Essa dimensão fica bastante clara no depoimento de Rita, quando diz que "se não tiver carro, do que vou abrir mão? Da ginástica, de levar os filhos ao colégio, do trabalho, de almoçar em casa...". A experiência da multidão ganha cores diversas conforme os meios. Na experiência dos coletivos, a multidão é uma presença diária, a pressão sobre os corpos faz com que se movam como um conjunto coeso, a proximidade física e mesmo a agressão são componentes do espaço. Já do ponto de vista do automóvel, a multidão é uma ameaça, o medo e a violência, um fantasma.

Mas o caldeirão em permanente ebulição que garante o movimento da cidade está sempre a ponto de explodir. Os terminais parecem ser o lado escuro e fantasmático da megacidade, o contraponto infernal das "fábricas de sonhos" que as estações ferroviárias uma vez representaram para a vida parisiense.

PAUla MonTERo é professora titular do Departamento de Antropologia da Universidade de São Paulo e pesquisadora do Cebrap. 